\title{
Time-saving effects using helicopter transportation: comparison to a ground transportation time predicted using a social navigation software
}

Ji Young Jang

Armed Forces Capital Hospital

Woo-Keun Kwon

Korea University Guro Hospital

Jong Ha Moon

Armed Forces Medical Command

Jun Seong Hwang

Armed Forces Medical Command

Yoon Jic Kim

Armed Forces Medical Command

Jang Hun Kim ( $\nabla$ jhkimns@naver.com )

Armed Forces Capital Hospital https://orcid.org/0000-0001-8557-1627

Research

Keywords: Ambulance, Ground, Helicopter, Navigation, Transportation

Posted Date: November 18th, 2020

DOI: https://doi.org/10.21203/rs.3.rs-105911/v1

License: (9) (i) This work is licensed under a Creative Commons Attribution 4.0 International License.

Read Full License

Version of Record: A version of this preprint was published at Medicine on July 9th, 2021. See the published version at https://doi.org/10.1097/MD.0000000000026569. 


\section{Abstract}

\section{Background}

Previous comparison studies regarding two types of transportation, helicopter (HEMS) versus ground emergency medical services (GEMS), have shown underlying heterogeneity as these options have completely different routes and consequent times with reference to one patient. To compare the two types of transportation on a case-by-case basis, we analyzed the retrospectively reviewed HEMS and predicted GEMS data using an open-source navigation software.

\section{Methods}

Patients transferred by military HEMS from 2016 to 2019 were retrospectively enrolled. The HEMS records on the time of notification, injury point and destination addresses, and time required were reviewed. The GEMS data on distance and the predicted time required were acquired using open-source social navigation systems. Comparison analyses between the two types of transportation were conducted. Further, linear logistic regression analyses were performed on the distance and time of the two options.

\section{Results}

A total of 183 patients were enrolled. There was no statistical difference $(p=0.3021)$ in the distance between the two types of transportation, and the HEMS time was significantly shorter than that of GEMS (61.31 vs. 116.92 minutes, $p<0.001$ ). The simple linear curves for HEMS and GEMS were separately secured, and two graphs presented the statistical significance $(p)$ as well as reasonable goodness-of-fit $\left(\mathrm{R}^{2}\right)$. In general, the HEMS graph demonstrates a more gradual slope and narrow distribution compared to that of GEMS.

\section{Conclusion}

Ideally, HEMS is identified as a better transportation modality because it has a shorter transportation time (56 minutes saved) and a low possibility of potential time delays (larger $\mathrm{R}^{2}$ ). With a strict patient selection, HEMS can rescue injured or emergent patients who are "out of the golden hour."

\section{Introduction}

It is widely accepted that the "Helicopter emergency medical service (HEMS)" has a shorter prehospital time compared to the "Ground EMS (GEMS)," and both services may be used to save an injured patient by facilitating their arrival at the hospital within the "golden hour."[1-3] Beyond the controversies on the costeffectiveness and practical outcomes of HEMS,[4-8] most clinicians would agree with the immediacy of HEMS especially when the patient is located in a rural area or in places that have poor ground traffic conditions.[9] 
Usually, when patients are injured, they have two transportation options: helicopter and ground ambulance. These have completely different routes and consequent time taken; therefore, they should be compared on a case-by-case basis.[10,11] Practically, the patient chooses one of the transportation options and the result of the other option cannot be secured. Therefore, the majority of the literature compare the two options with underlying heterogeneity.[12-15]

If we have the injured patient's "exact address" and the "day and time" when the transportation began, we can predict the distance and time of GEMS by using an open-source navigation software.[16] Since the Medical Emergency Operating Center (MEOC) of the Korean Armed Forces Medical Command provides a helicopter transportation system for military medical welfare and regards it as one of the important military missions or operations, the data on patient location and time can be precisely recorded.[17] By reviewing the records and comparing the data, we can directly calculate "the practical time saved," which may influence the decision on the transportation modalities in clinical settings. Here, we attempted to secure the ideal linear curve of the distance and time of the two transportation systems, and calculate the exact time saved by using an open-source social navigation system.

\section{Methods}

\section{Patients}

We retrospectively reviewed the patients who were notified of the MEOC and transported by military HEMS from January 2016 to December 2019. The inclusion criteria were as follows: (1) patients who had the exact injury point address and time of notification, and (2) were transferred by military medical helicopters (KUH-1, Korea Aerospace Industries, LTD., Gyeongsangnam-do, Korea). Patients were excluded if they used public helicopters, the exact injury point address was not assessable (military secrets), or ground transportation was not available for comparison such as those at high mountains or islands. Data on the patients' general demographics were obtained including age, sex, disease conditions, detailed transportation courses, and their destinations. The current study was approved by the Institutional Review Board of the Human Research Center of the Korean Armed Forces Medical Command (AFMC-20-IRB-024), and informed consent was waived due to the retrospective design.

\section{Transportation settings}

In the military medical system, when patients are injured, a rapid transportation system (from the injury point to the suitable hospital) is operated after direct notification to the MEOC. Usually, the nearest military doctor arrives at the injury point, and subsequently makes a decision regarding the transportation modality based on his experience and information from the navigation software. If the situation and time required by GEMS are acceptable, direct GEMS starts from the injury point to the nearest emergency center (G1). If they are not acceptable, HEMS could be started through two different models depending on the availability of injury points on the helicopter's landing: (1) direct pick-up, and (2) stopover. There are five distributed military helicopter emergency commands, and the nearest helicopter departs to the injury point or helipad that is closest to the patient. The transport settings and model are illustrated in Figure 1. 


\section{Data acquisition of HEMS and GEMS}

We obtained data by reviewing the records of HEMS transportation including the day and time of notification, injury point address, the address of the nearest helipad (if used), each time required, and destinations. Figure 1 presents the categorical time and distance of HEMS.

The distance and predictive time required for GEMS transportation are acquired using open-source social navigation systems. Every distance was measured using an online map software (http://map.naver.com, NAVER Co., Gyeonggi-do, Korea), and the predicted time required is taken from another navigation software (http://tmap.co.kr, SK TELECOM Co., Seoul, Korea) as it provides day-by-day and time-by-time predictions. Figure 2 illustrates the distance and time comparisons between the two transportation systems.

\section{Statistical analysis}

Continuous values are presented as mean and standard deviation, and categorical variable data are presented as frequency and percentages. Nonparametric Wilcoxon signed rank tests were performed to compare the baseline parameters (distance and time) of the two types of transportation. To secure the ideal linear curve between the distance and time parameters in the two transportation systems, simple linear regression analyses were performed. Statistical significance was considered at $p<0.05$. Statistical analyses were performed using a standard software (version 23.0, SPSS, IBM, Chicago, IL, USA).

\section{Results}

In total, 326 patients notified MEOC of their emergencies. Of the 326 patients, 143 were excluded for utilizing a public helicopter $(n=74)$, unavailability of ground transportation $(n=25)$, and inaccessibility of the injury point address $(n=44)$. Finally, 183 patients were enrolled, and the flowchart of patient enrollment is shown in Fig. 3.

The general demographics of the sample are shown in Table 1. Owing to military secrets, several pieces of information are blinded. Of the 183 patients, 124 were transported after waiting for the arrival of the helicopter at the injury point (Situation A), whereas 59 patients were moved to the nearest helipad for safe helicopter landing (Situation B). As shown in Fig. 4A, there was no statistical difference in the distance between the two transportation systems $(p=0.3021)$; however, the transportation time of HEMS was significantly shorter than that of GEMS $(61.31 \pm 22.03$ vs. $116.92 \pm 33.34, p<0.001)$. 
Table 1

General demographics of the enrolled samples

\begin{tabular}{|ll|}
\hline Enrolled Patients $(\mathbf{n}=\mathbf{1 8 3})$ & \\
\hline General & blind \\
\hline Age & blind \\
\hline Sex & \\
\hline Disease conditions & $40(21.86 \%)$ \\
\hline Extremity injury & $25(13.66 \%)$ \\
\hline Airway, breathing problem & $18(9.84 \%)$ \\
\hline Traumatic brain injury & $18(9.84 \%)$ \\
\hline Acute abdomen & $17(9.29 \%)$ \\
\hline Multiple trauma & $12(6.56 \%)$ \\
\hline Arrest, including hanging & $11(6.01 \%)$ \\
\hline Stroke (ischemic/hemorrhagic) & $7(3.83 \%)$ \\
\hline Pneumothorax & $5(2.73 \%)$ \\
\hline Myocardial infarction & $5(2.73 \%)$ \\
\hline Shock & $3(1.64 \%)$ \\
\hline Spinal cord injury & $22(12.02 \%)$ \\
\hline Others & \\
\hline Situation & $12(6.56 \%)$ \\
\hline A: Direct pick-up & $93(4.92 \%)$ \\
\hline B: Stopover & $124(67.76 \%)$ \\
\hline Helicopter starting point (blinded) & \\
\hline CC & $59(32.24)$ \\
\hline PC & \\
\hline YG & \\
\hline YI & \\
\hline HL & \\
\hline Distance (kilometers) & \\
\hline
\end{tabular}




\begin{tabular}{|lll|}
\hline Enrolled Patients $(\mathbf{n}=\mathbf{1 8 3})$ & \\
\hline Time (minutes) & $61.31 \pm 22.03$ & $116.92 \pm 33.34$ \\
\hline Time saved (minutes) & $55.61 \pm 27.71$ & \\
\hline
\end{tabular}

To integrate the two different situations, we compared the " $\mathrm{H} 1$ (helicopter from helicopter emergency command to the nearest helipad)" and "G2 (ground ambulance from injury point to the nearest helipad)" time in the "stopover situation (B) in Fig. 1." As shown in Fig. 4B, among 59 patients who moved to the nearest helipad to have access to HEMS, every H1 time is larger than that of G2 (except one case). In other words, the helicopter's waiting only occurred in one case (marked with red spot; 5 minutes); therefore, the time of HEMS $(\mathrm{H})$ was defined as the sum of $\mathrm{H} 1$ and $\mathrm{H} 2$, and that of GEMS $(\mathrm{G})$ was defined as $\mathrm{G} 1$ ( $\mathrm{G} 2$ ignored).

The results of the simple linear regression analyses are presented in Table 2, and their graphs are plotted in Figs. 5 and 6. The ideal curves for HEMS and GEMS are separately secured with statistical significance as well as reasonable goodness-of-fit (Fig. 5). Compared to GEMS (B), HEMS (A) shows a better fit in terms of gradual slope and narrow distributions.

Table 2

The results of simple linear regression analyses

\begin{tabular}{|lllll|}
\hline Results & HEMS & GEMS & $\begin{array}{l}\text { Time saved } \\
\text { (H-distance) }\end{array}$ & $\begin{array}{l}\text { Time saved } \\
\text { (G-distance) }\end{array}$ \\
\hline Slope & 0.2739 & 0.5483 & 0.04327 & 0.2073 \\
\hline $\begin{array}{l}\text { Std. } \\
\text { Error }\end{array}$ & 0.01106 & 0.02979 & 0.02896 & 0.03902 \\
\hline $95 \% \mathrm{Cl}$ & 0.2520 to 0.2957 & 0.4895 to 0.6071 & -0.01386 to 0.1004 & 0.1303 to 0.2843 \\
\hline $\mathrm{Y}$ & 26.76 & 50.71 & 50.15 & 30.59 \\
\hline $\mathrm{X}$ & -97.73 & -92.48 & -1159 & -147.6 \\
\hline Equation & $\mathrm{Y}=0.2739^{*} \mathrm{X}+$ & $\mathrm{Y}=0.5483^{\star} \mathrm{X}+$ & $\mathrm{Y}=0.04327{ }^{*} \mathrm{X}+$ & $\mathrm{Y}=0.2073^{\star} \mathrm{X}+$ \\
\hline $\mathrm{R}{ }^{2}$ & 26.76 & 50.71 & 50.15 & 30.59 \\
\hline $\mathrm{P}$ value & $\mathbf{0 . 7 7 2 2}$ & $\mathbf{0 . 6 5 1 8}$ & 0.01219 & 0.1348 \\
\hline
\end{tabular}

The times saved according to the distances were independently acquired (Fig. 6). Only significance is noted based on ground kilometers (B); however, both curves show poor goodness-of-fit (explanation abilities). 
In our results, the average time required by HEMS was 61 minutes, which was 56 minutes shorter compared to that required by GEMS. Further, we successfully secured ideal linear curves for the two transportation systems (between distance and time required). By using the curves and exact injury point and destination addresses, we can finally calculate the time saved, which can be a good reference for making a decision on the transportation modality.

HEMS was originally used as air transport in military evacuation during the Korean War, and its use in civilian situations was initiated in the 1960s in the United States.[18, 19] Since then, the HEMS has been successfully utilized in the transportation of injured victims to trauma centers in several advanced countries (especially those with broad territories), and the role of air transportation in long distances, hostile environments, and difficult geographical areas that cannot be accessed by ground ambulances has been undisputed.[14] However, the setting for HEMS requires a great deal of human as well as other fundamental resources after social agreements. Further, the effectiveness of HEMS remains controversial, such as in countries with small territories with good ground traffic conditions.[7, 9, 15, 19] Several studies have highlighted the importance of reducing the helicopter transportation of near-hospital injuries and over-triage of minor injury patients for air transportation in order to achieve better costeffectiveness and practical mortality or disability reductions in HEMS.[7, 8, 20]

In South Korea, 17 regional trauma centers have been evenly distributed across the country for the provision of superior medical services to patients with emergent and traumatic diseases. In these centers, several efforts have been made to utilize helicopter transport including a pilot project referred to as "Doctor Heli 2011"; [12] however, HEMS failed to be set-up such that only 237 patients of a total of 139,072 major medical emergency patients were airlifted by helicopters $(0.001 \%)$.[21] This might be related to the poor fundamental support from the government and insufficient social understanding that cost-effectiveness cannot be fully achieved due to the geographic characteristics of South Korea (small territory, high urban population density, and excellent road-traffic networks). Currently, HEMS is only operated in four institutions, and a nationwide expansion of the service is mandatory.

In contrast, in 2015, the MEOC set up a military HEMS and managed every case of emergency notification. From 2015 to 2019, a total of 573 patients were notified of their transportation from camps (or initial frontline medical facilities) to a suitable emergency center by HEMS. A relatively large volume of helicopter transportation is available in a single command (compared to the total number of regional trauma centers) as the military HEMS can be fully equipped, as covered by the Ministry of National Defense budget. Furthermore, since military corps are usually located on the frontlines that are far from urban areas, the distance from the injury point to the hospital makes it suitable to utilize HEMS. To date, the MEOC directly offers HEMS for military medical welfare as well as preparation for handling a potential mass casualty situation due to injuries that occur during wartime combat. In addition, as the MEOC does not pursue profits from the utilization of HEMS, a comparison between the two modalities can be objectively conducted. Here, we compared the two transportation modalities (helicopter vs. ground ambulance) and identified several different characteristics. 
First, both types of transportation can be started simultaneously (after notification); however, the starting points are different in that a ground ambulance is usually directly available from the injury point, whereas a helicopter should move from the command to the injury point to begin patient transportation. Therefore, each transportation has a completely different route. As shown in Fig. 1, helicopters usually need additional transfer, indicated as " $\mathrm{H} 1$ "; however, $\mathrm{H} 2$ can be shortened by using an air route. On the other hand, if ground transportation has to be used in this case, then the transportation directly starts by using $\mathrm{G} 2$, which is dependent on the road condition and traffic situation. However, the majority of previous studies have compared two modalities by considering different patient groups.[14, 15, 22, 23] This might induce a significant heterogeneity between the groups, and objective comparison cannot be secured. By using a navigation software, we obtained each patient's "practically used airline route" and "predicted ground traffic route," and finally, the groups indicated a similar range of distance without any significance $(p=0.3021$, Fig. $4 A)$.

Second, the practical HEMS pre-hospital time was significantly shorter than the predicted GEMS prehospital time (Fig. 4A, p < 0.0001). It is clear that approximately 56 minutes can be saved by using HEMS when the injury points are located on an average of 120 kilometers (or 116 minutes) far from the hospital. Beyond controversies, the "golden hour" is a well-known lexicon among trauma surgeons and EMS providers, and the underlying tenet of this adage suggests an injured patient has 60 minutes to receive definitive care from time of injury, after which chances of morbidity and mortality significantly increase.[3, $24,25]$ In our results, HEMS can enable the injured patients who are in over one-hour distances from hospital to arrive at the emergency centers within the "golden hour."

Third, both types of transportation are significantly associated with a simple linear curve, but the slope of the graphs differ ( 0.2739 of HEMS vs. 0.5483 in GEMS, Fig. 5). It can be interpreted that the average HEMS speed is twice as fast as that of GEMS. The greater the distance from the hospital, the more the time that can be saved. As mentioned, only a few studies that compare the slope or curves (between distance and time) of the modalities have been reported, $[22,26]$ and to the best of our knowledge, the current result is the first curve in Korean HEMS circumstances. Furthermore, the $\mathrm{R}^{2}$ parameter, which refers to the goodness-of-fit of the ideal curve, is higher in HEMS (0.7722 in HEMS vs. 0.6518 in GEMS). [27] It may be inferred that the HEMS is accompanied by a lower possibility of transportation delays and is less dependent on unpredictable interfering factors. Beyond the controversies on cost-effectiveness, HEMS can be regarded as an ideal "predictable" transfer modality for patients who are in over an-hour distances.

In fact, we failed to secure the ultimate curve for the time saved as it was not significant and displayed poor $\mathrm{R}^{2}$ parameters (Fig. 6). As the two modalities have totally different routes and consequent curves, they cannot be easily integrated into one simple curve. Instead, by using two curves, we can assess the time saved, which is the final value for a physician to use when deciding on the transportation modality. The HEMS graph (Fig. 5A) has both significance and goodness-of-fit; it can be used as the basic curve for Korean HEMS circumference of Gyeonggi-Gangwon province. By combining it with the social navigation software, each transportation time can be minutely analyzed. A future development of a software or 
application may provide wide accessibility for EMS-involved persons such as physicians, emergency medical technicians, and EMS providers.

The current study has several limitations. First, cost-effectiveness was not analyzed. Because of the distinct characteristics of military medicine, the HEMS can be utilized without considering the operating profits. A comparison of budgets between HEMS and GEMS can be a good reference for policymakers. Second, patient factors, including the severity of injury and outcomes, were not included. The analyses were based on the documentation from MEOC, which precisely recorded the information on "helicopter transportation," including the injury point address and destination, and each time required. The detailed patient information could only be assessed after reviewing each destination hospitals' medical records, which were not included in this study. Third, the results or graphs of the current study cannot be generalized since the road traffic condition and hospital distribution may differ among the provinces and/or countries. However, the flatform of the study can be easily adapted to other situations using retrospective data and navigation software.

\section{Conclusion}

We analyzed the time required for two modes of transportation by using retrospectively reviewed HEMS data and navigation-based GEMS predicted data. Two simple HEMS and GEMS linear curves were successfully acquired with significance and goodness-of-fit. Ideally, HEMS was identified as a better transportation modality because of the shorter transportation time and a low possibility of potential time delays. With a strict patient selection, HEMS can be used to salvage injured or emergent patients who are "out of the golden hour."

\section{Abbreviations}

HEMS: Helicopter emergency medical service

GEMS: Ground emergency medical service

MEOC: Medical Emergency Operating Center

\section{Declarations}

\section{ETHICS APPROVAL AND CONSENT TO PARTICIPATE}

The current study was approved by the Institutional Review Board of the Human Research Center of the Korean Armed Forces Medical Command (AFMC-20-IRB-024), and informed consent was waived due to the retrospective design.

\section{CONSENT FOR PUBLICATION}

Not applicable. 


\section{AVAILABILITY OF DATA AND MATERIAL}

The data and materials used in the current study are all available from the corresponding author upon reasonable request.

\section{COMPETING INTERESTS}

The authors have no personal, financial, or institutional interest in any of the drugs, materials, or devices described in this article.

\section{FUNDING}

The authors did not receive any funding.

\section{AUTHORS' CONTRIBUTIONS}

JH Kim, JY Jang, and JS Hwang obtained the clinical data and performed the postprocessing of the neuroimaging studies. YJ Kim and JH Moon obtained the clinical data. JH Kim, WK Kwon, JH Moon and JY Jang designed the study, interpreted the data, and wrote the final draft of the manuscript.

\section{ACKNOWLEDGEMENTS}

None.

\section{References}

1. Harmsen AM, Giannakopoulos GF, Moerbeek PR, Jansma EP, Bonjer HJ, Bloemers FW. The influence of prehospital time on trauma patients outcome: a systematic review. Injury. 2015;46 4:602-9; doi: 10.1016/j.injury.2015.01.008.

2. Brown JB, Rosengart MR, Forsythe RM, Reynolds BR, Gestring ML, Hallinan WM, et al. Not all prehospital time is equal: Influence of scene time on mortality. J Trauma Acute Care Surg. 2016;81 1:93-100; doi: 10.1097/TA.0000000000000999.

3. Schroeder PH, Napoli NJ, Barnhardt WF, Barnes LE, Young JS. Relative Mortality Analysis Of The "Golden Hour": A Comprehensive Acuity Stratification Approach To Address Disagreement In Current Literature. Prehosp Emerg Care. 2019;23 2:254-62; doi: 10.1080/10903127.2018.1489021.

4. Bledsoe BE, Wesley AK, Eckstein M, Dunn TM, O'Keefe MF. Helicopter scene transport of trauma patients with nonlife-threatening injuries: a meta-analysis. J Trauma. 2006;60 6:1257-65; discussion 65-6; doi: 10.1097/01.ta.0000196489.19928.c0.

5. Brathwaite CE, Rosko M, McDowell R, Gallagher J, Proenca J, Spott MA. A critical analysis of onscene helicopter transport on survival in a statewide trauma system. J Trauma. 1998;45 1:140-4; discussion 4-6; doi: 10.1097/00005373-199807000-00029. 
6. Cunningham P, Rutledge R, Baker CC, Clancy TV. A comparison of the association of helicopter and ground ambulance transport with the outcome of injury in trauma patients transported from the scene. J Trauma. 1997;43 6:940-6; doi: 10.1097/00005373-199712000-00013.

7. Andruszkow H, Frink M, Zeckey C, Krettek C, Hildebrand F, Mommsen P. Merits and capabilities of helicopter emergency medical service (HEMS) in traumatized patients. Technol Health Care. 2012;20 5:435-44; doi: 10.3233/THC-2012-0691.

8. Delgado MK, Staudenmayer KL, Wang NE, Spain DA, Weir S, Owens DK, et al. Cost-effectiveness of helicopter versus ground emergency medical services for trauma scene transport in the United States. Ann Emerg Med. 2013;62 4:351-64 e19; doi: 10.1016/j.annemergmed.2013.02.025.

9. Stewart KE, Cowan LD, Thompson DM, Sacra JC, Albrecht R. Association of direct helicopter versus ground transport and in-hospital mortality in trauma patients: a propensity score analysis. Acad Emerg Med. 2011;18 11:1208-16; doi: 10.1111/j.1553-2712.2011.01207.x.

10. Poon WS, Li AK. Comparison of management outcome of primary and secondary referred patients with traumatic extradural haematoma in a neurosurgical unit. Injury. 1991;22 4:323-5; doi: 10.1016/0020-1383(91)90016-8.

11. Urdaneta LF, Miller BK, Ringenberg BJ, Cram AE, Scott DH. Role of an emergency helicopter transport service in rural trauma. Arch Surg. 1987;122 9:992-6; doi: 10.1001/archsurg.1987.01400210030003.

12. Kim J, Heo Y, Lee JC, Baek S, Kim Y, Moon J, et al. Effective transport for trauma patients under current circumstances in Korea: a single institution analysis of treatment outcomes for trauma patients transported via the domestic 119 service. J Korean Med Sci. 2015;30 3:336-42; doi: 10.3346/jkms.2015.30.3.336.

13. Chen X, Gestring ML, Rosengart MR, Peitzman AB, Billiar TR, Sperry JL, et al. Logistics of air medical transport: When and where does helicopter transport reduce prehospital time for trauma? J Trauma Acute Care Surg. 2018;85 1:174-81; doi: 10.1097/TA.0000000000001935.

14. Aiolfi A, Benjamin E, Recinos G, De Leon Castro A, Inaba K, Demetriades D. Air Versus Ground Transportation in Isolated Severe Head Trauma: A National Trauma Data Bank Study. J Emerg Med. 2018;54 3:328-34; doi: 10.1016/j.jemermed.2017.11.019.

15. Galvagno SM, Jr., Haut ER, Zafar SN, Millin MG, Efron DT, Koenig GJ, Jr., et al. Association between helicopter vs ground emergency medical services and survival for adults with major trauma. JAMA. 2012;307 15:1602-10; doi: 10.1001/jama.2012.467.

16. Park KD, Seo SJ, Oh CH, Kim SH, Cho JM. The Effectiveness Evaluation of Helicopter Ambulance Transport among Neurotrauma Patients in Korea. J Korean Neurosurg Soc. 2014;56 1:42-7; doi: 10.3340/jkns.2014.56.1.42.

17. Kim S. The Formation of the Military Medical System of the Korean People's Army and the Military Medical Officer. Uisahak. 2017;26 3:379-416; doi: 10.13081/kjmh.2017.26.379.

18. Thomas SH, Cheema F, Wedel SK, Thomson D. Trauma helicopter emergency medical services transport: annotated review of selected outcomes-related literature. Prehosp Emerg Care. 2002;6 3:359-71; doi: 10.1080/10903120290938508. 
19. Thomas SH. Helicopter EMS transport outcomes literature: annotated review of articles published 2004-2006. Prehosp Emerg Care. 2007;11 4:477-88; doi: 10.1080/10903120701537097.

20. Vercruysse GA, Friese RS, Khalil M, Ibrahim-Zada I, Zangbar B, Hashmi A, et al. Overuse of helicopter transport in the minimally injured: A health care system problem that should be corrected. J Trauma Acute Care Surg. 2015;78 3:510-5; doi: 10.1097/TA.0000000000000553.

21. Emergency Medical Service Anual Report, 2012. In. National Emergency Medical Center; 2013.

22. Nicholl JP, Beeby NR, Brazier JE. A comparison of the costs and performance of an emergency helicopter and land ambulances in a rural area. Injury. 1994;25 3:145-53; doi: 10.1016/00201383(94)90151-1.

23. Tortella BJ, Sambol J, Lavery RF, Cudihy K, Nadzam G. A comparison of pediatric and adult trauma patients transported by helicopter and ground EMS: managed-care considerations. Air Med J. 1996;15 1:24-8; doi: 10.1016/s1067-991x(96)90015-2.

24. Tallon JM. The "golden hour" paradigm. Acad Emerg Med. 2002;9 7:760; author reply doi: 10.1111/j.1553-2712.2002.tb02159.x.

25. Sasada M, Williamson K, Gabbott D. The golden hour and pre-hospital trauma care. Injury. 1995;26 3:215-6; doi: 10.1016/0020-1383(95)90061-6.

26. Stowell A, Bobbia X, Cheret J, Genre Grandpierre R, Moreau A, Pommet S, et al. Out-of-hospital Times Using Helicopters Versus Ground Services for Emergency Patients. Air Med J. 2019;38 2:100-5; doi: 10.1016/j.amj.2018.11.017.

27. Alexander DL, Tropsha A, Winkler DA. Beware of R(2): Simple, Unambiguous Assessment of the Prediction Accuracy of QSAR and QSPR Models. J Chem Inf Model. 2015;55 7:1316-22; doi: 10.1021/acs.jcim.5b00206.

\section{Figures}




\section{A. Direct pick-up}

Helicopter Emergency Command

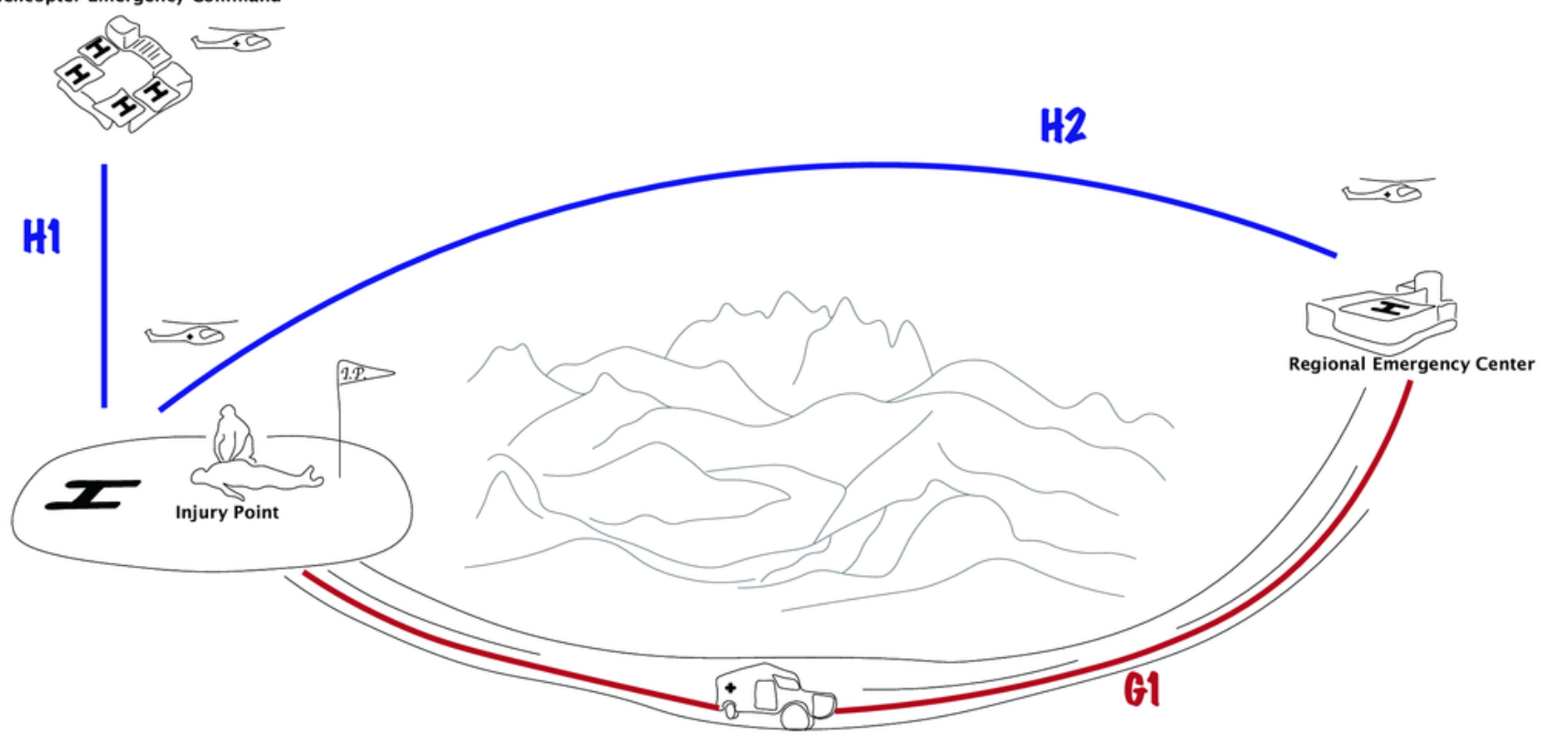

\section{B. Stopover}

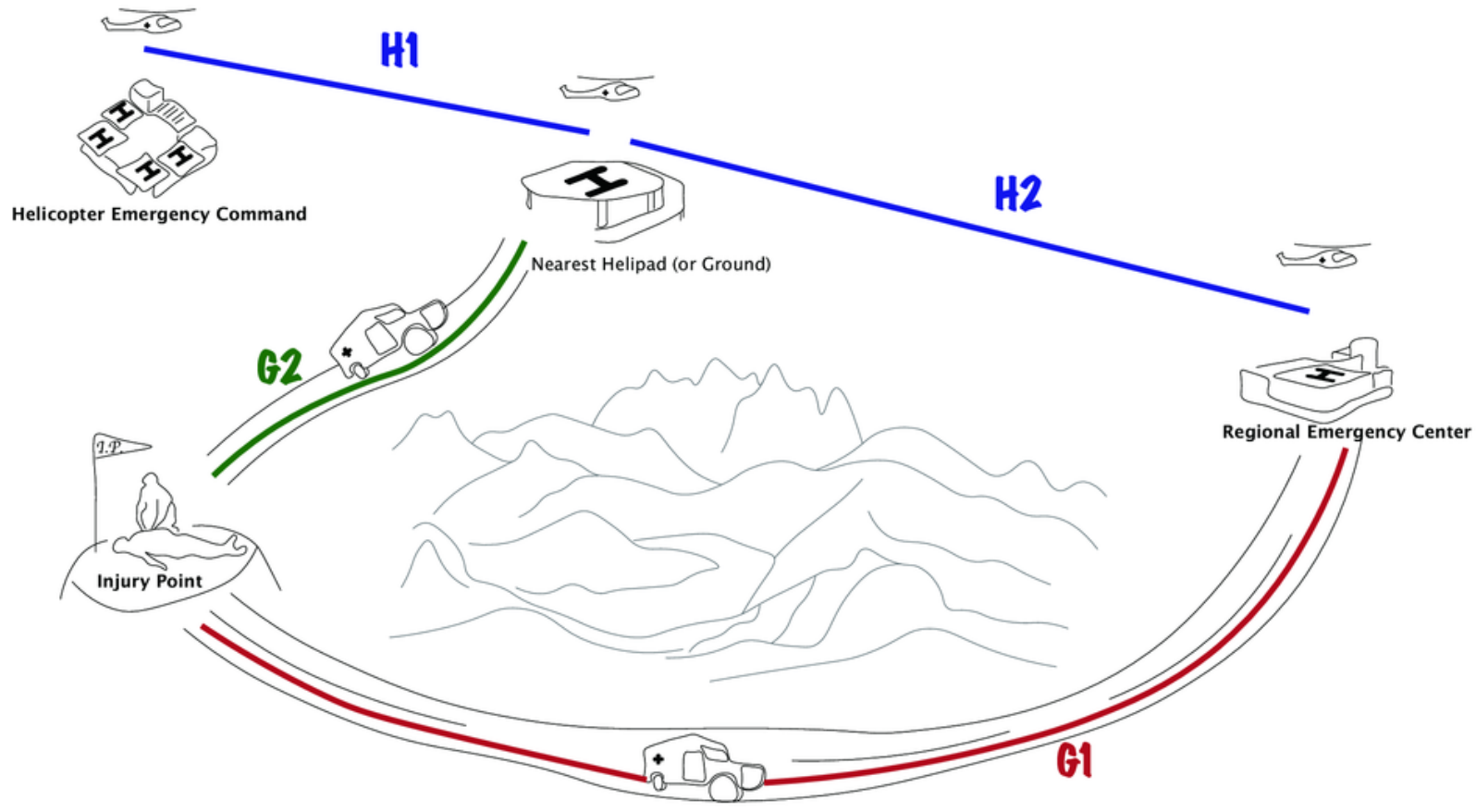

\section{Figure 1}

Two situations of helicopter transportation. If there is a helicopter landing at the injury point $(A)$, the patient can be picked up directly. If there is no landing (B), the helicopter should stop over at the nearest helipad to pick up the patient. 


\section{A. Direct pick-up}

Helicopter Emergency Command
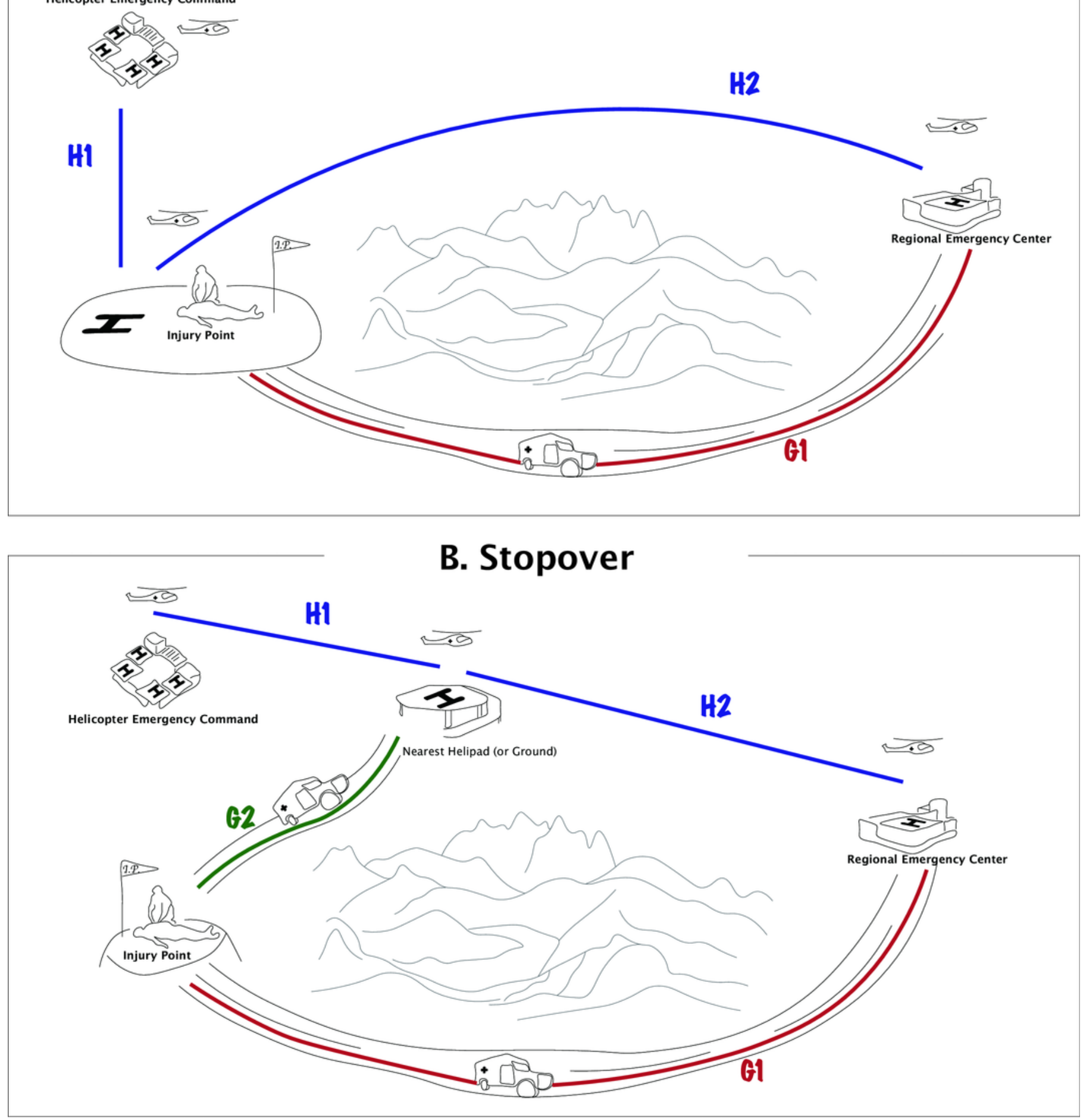

\section{Figure 1}

Two situations of helicopter transportation. If there is a helicopter landing at the injury point $(A)$, the patient can be picked up directly. If there is no landing (B), the helicopter should stop over at the nearest helipad to pick up the patient. 


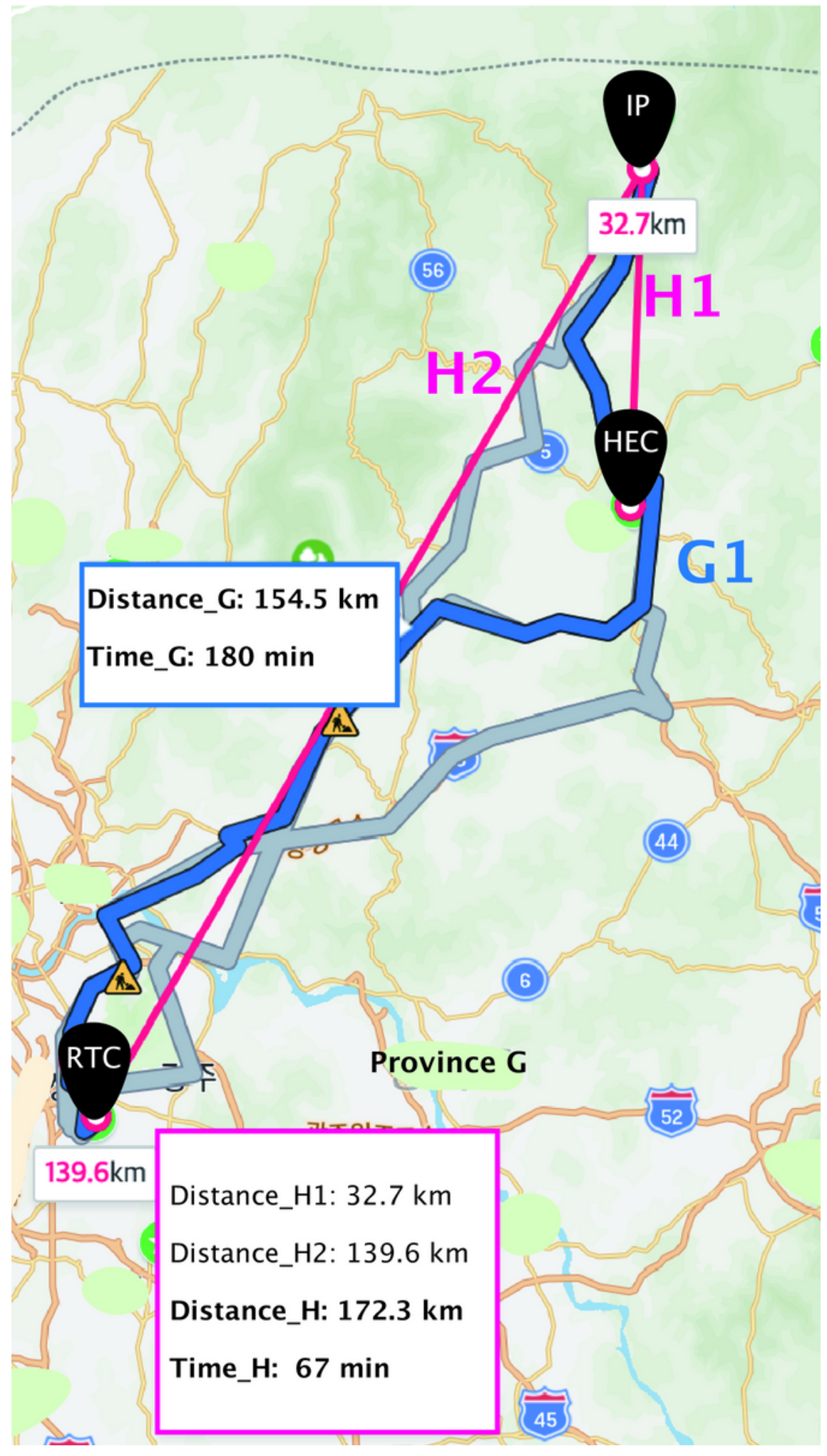

Figure 2

The captured image of social navigation software. The direct airline distances ( $\mathrm{H} 1$ : helicopter command to injury point, $\mathrm{H} 2$ : injury point to destination) and practical road distance (G1) are measured. The time required by ground is predicted using a navigation software, whereas that of the helicopter is acquired by retrospective chart review. 


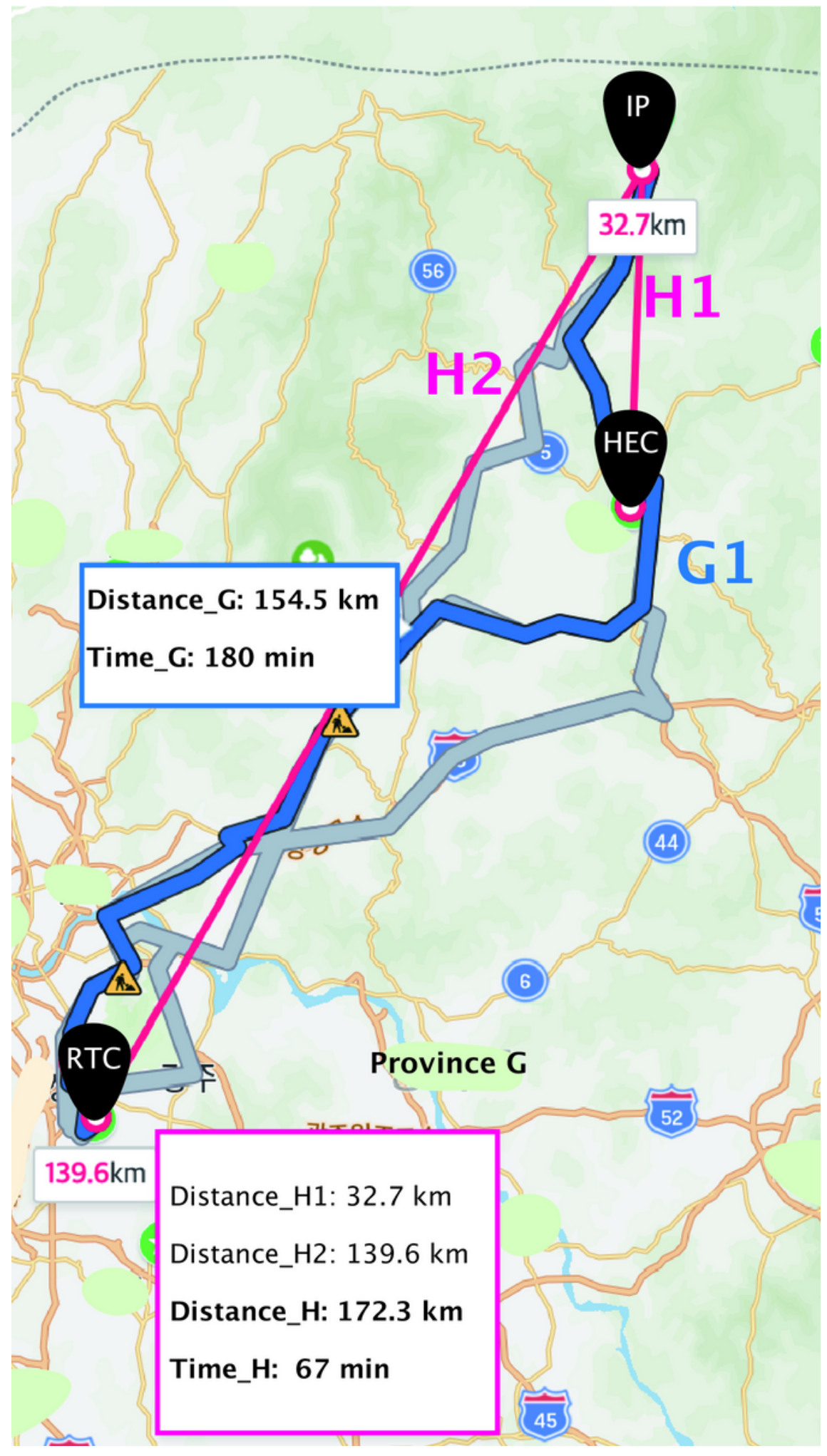

Figure 2

The captured image of social navigation software. The direct airline distances ( $\mathrm{H} 1$ : helicopter command to injury point, $\mathrm{H} 2$ : injury point to destination) and practical road distance (G1) are measured. The time required by ground is predicted using a navigation software, whereas that of the helicopter is acquired by retrospective chart review. 


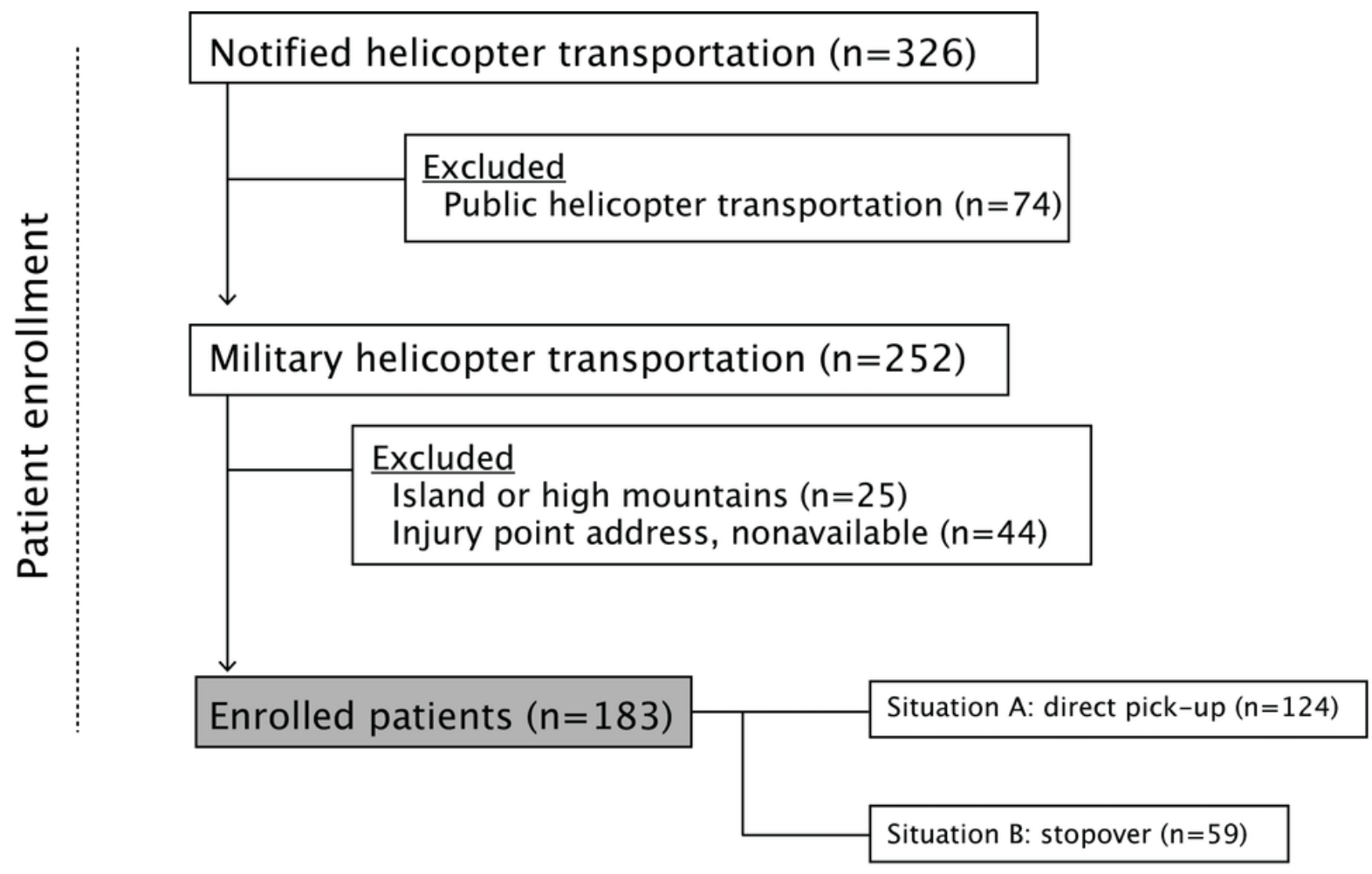

Figure 3

The flowchart of patient enrollment.

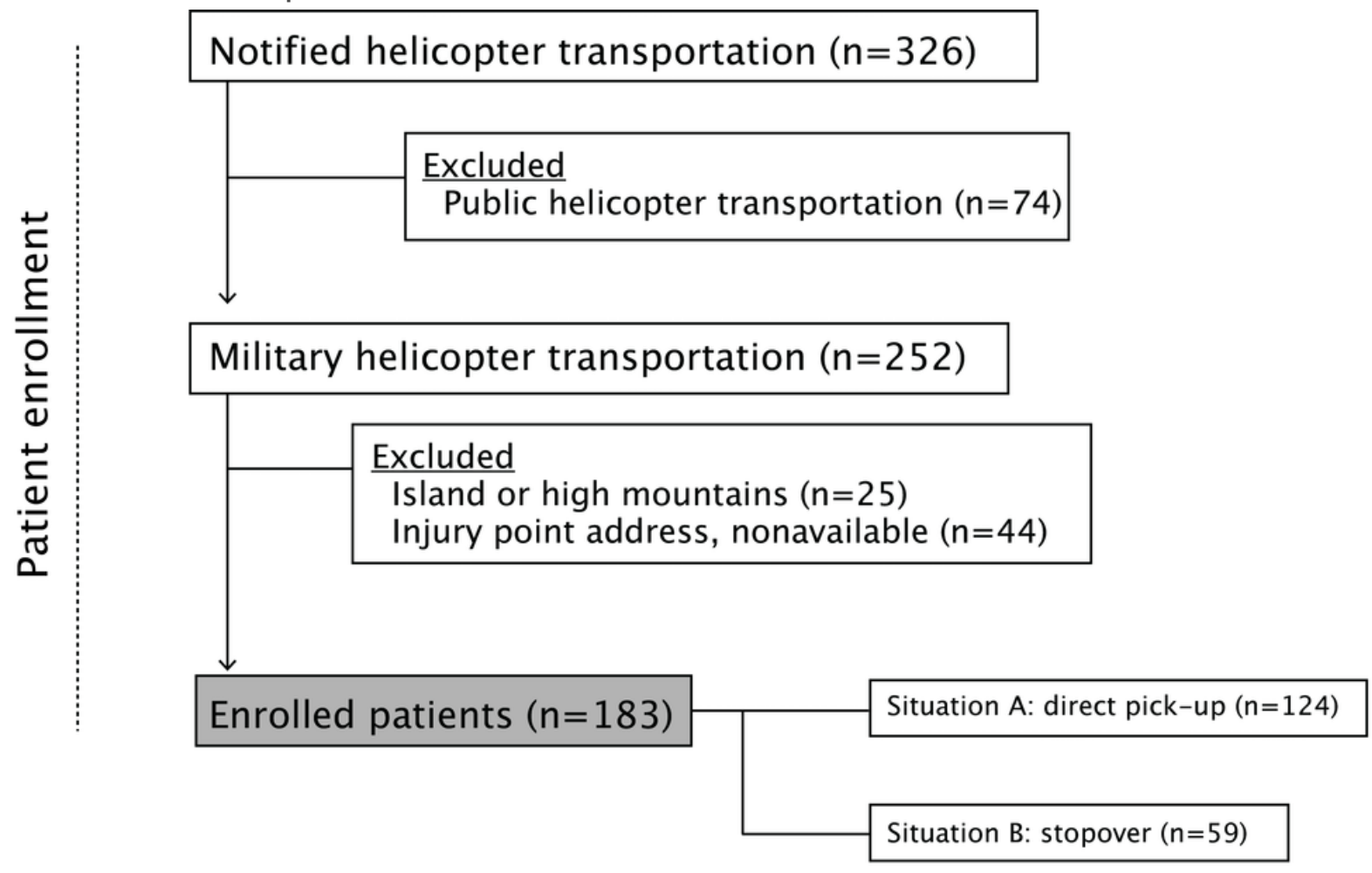

Figure 3

The flowchart of patient enrollment. 


\section{Distance}

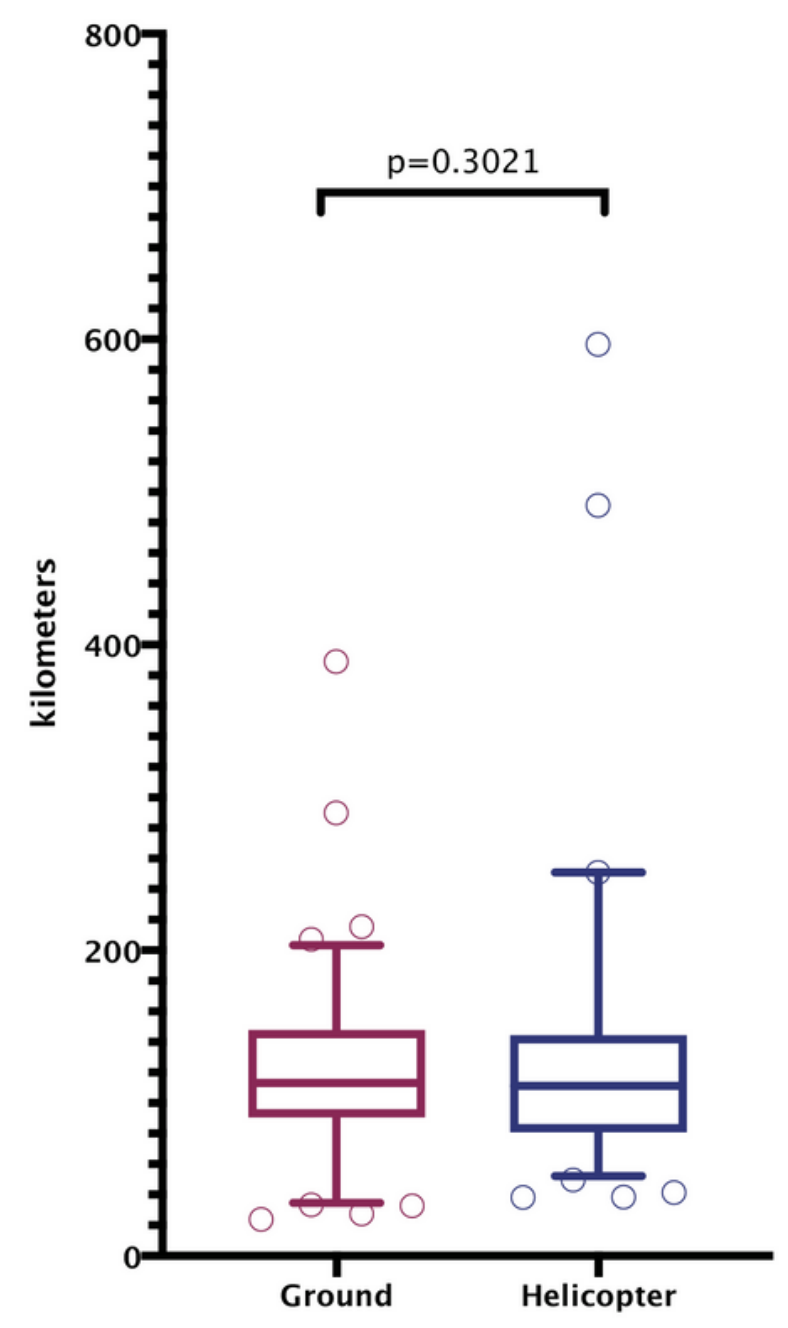

\section{Time}

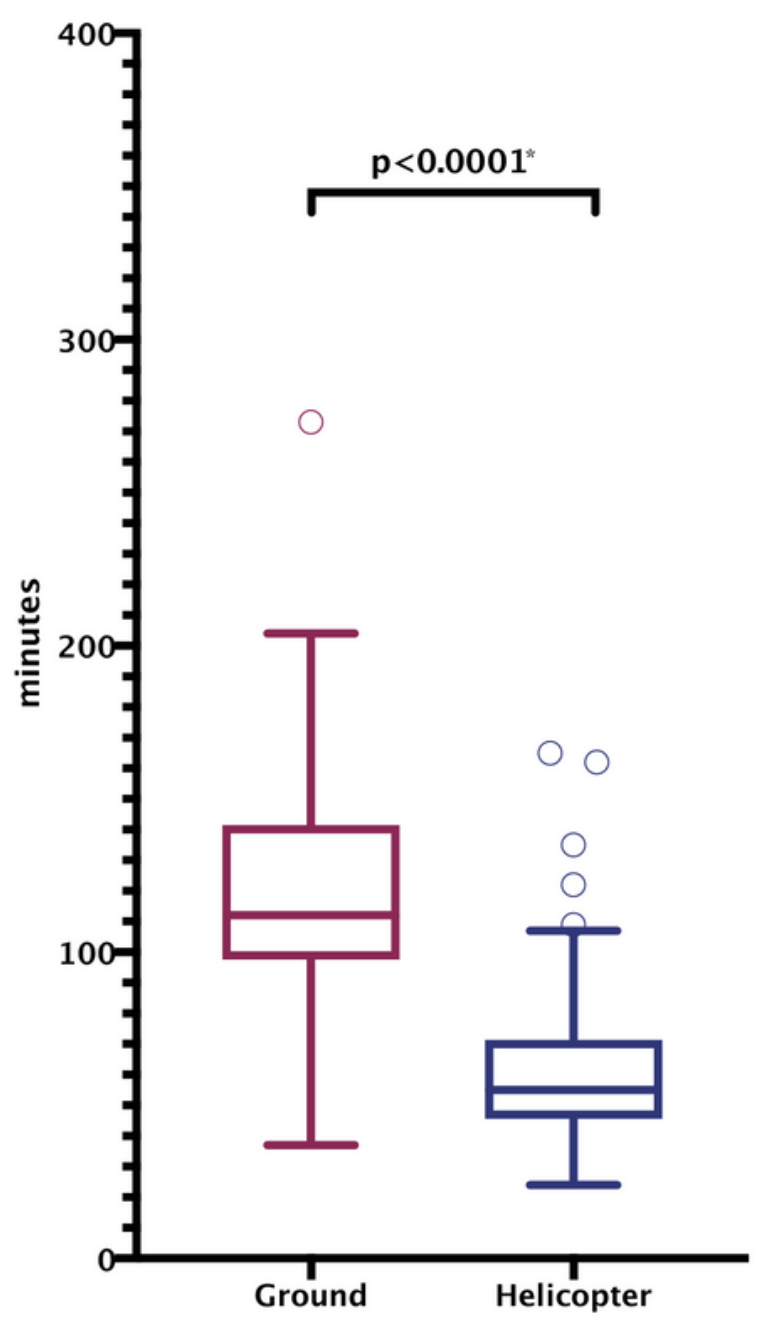

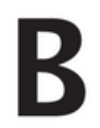

Helicopter's waiting time

(G2-H1)
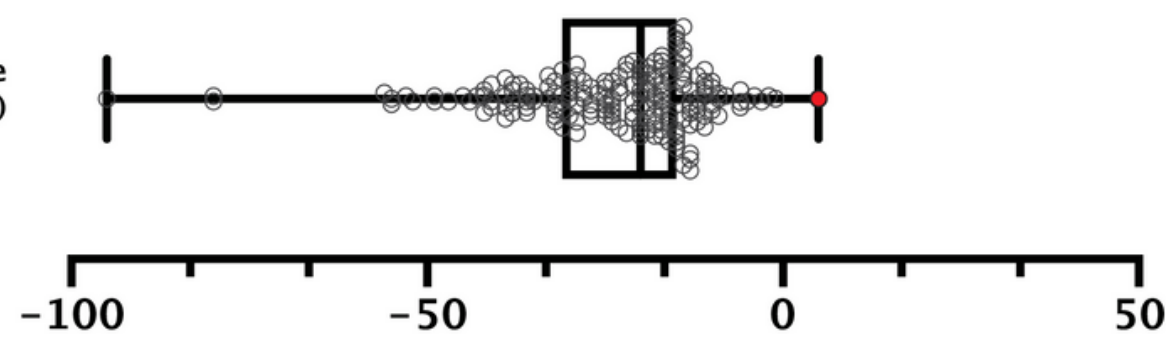

Figure 4

The plots of the distance and time of the two types of transportation with the results of the Wilcoxon signed rank tests $(A)$ and helicopters' waiting time (B). 


\section{Distance}

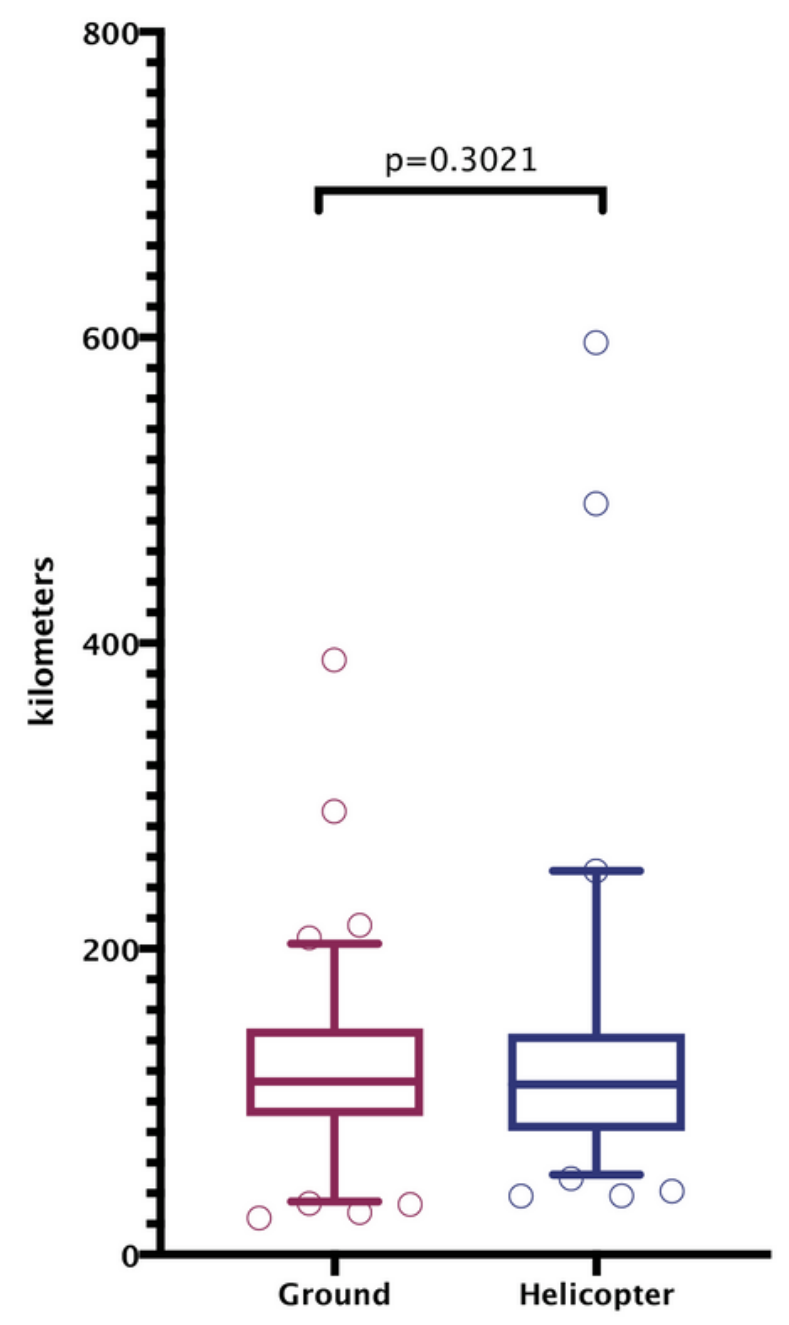

\section{Time}

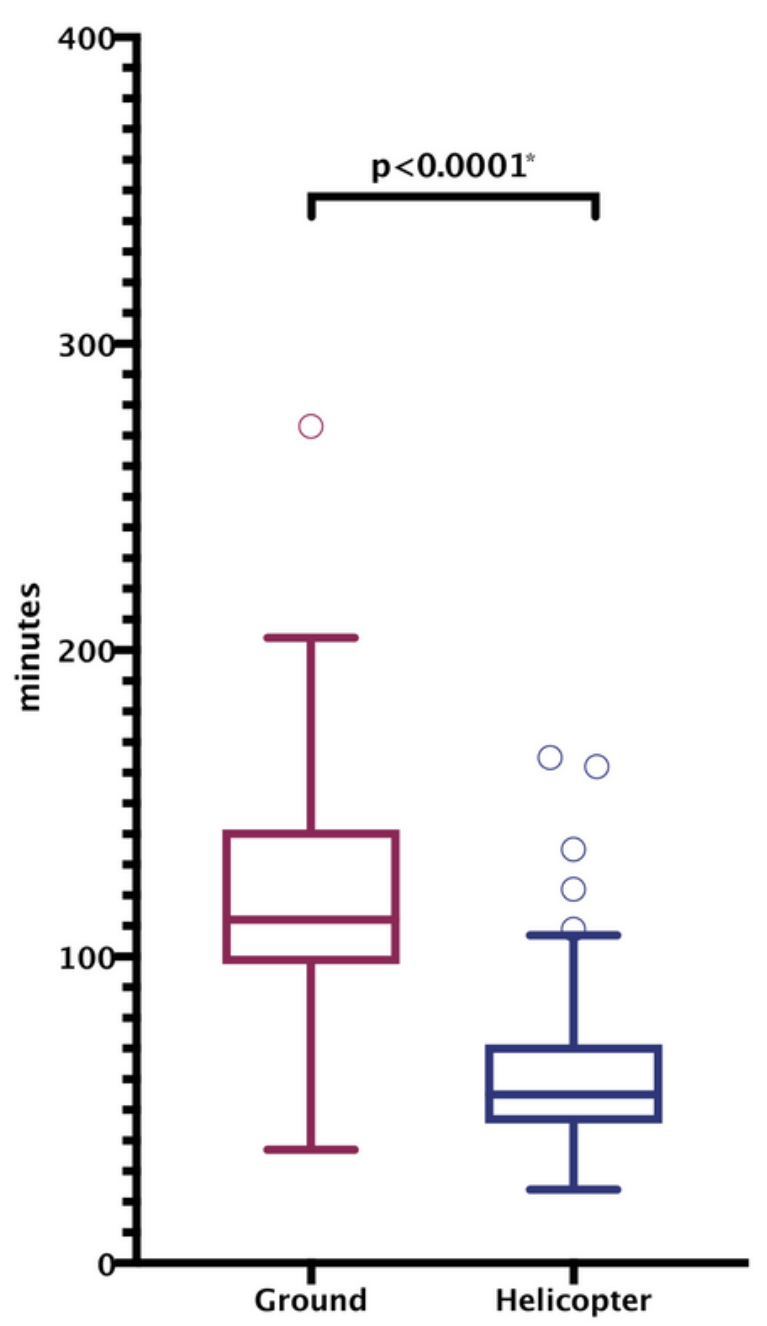

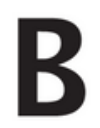

Helicopter's waiting time

(G2-H1)
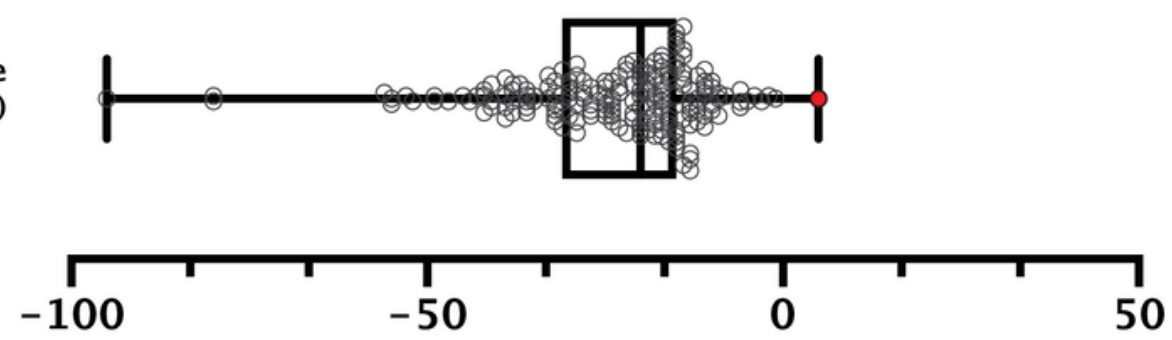

Figure 4

The plots of the distance and time of the two types of transportation with the results of the Wilcoxon signed rank tests $(A)$ and helicopters' waiting time (B). 

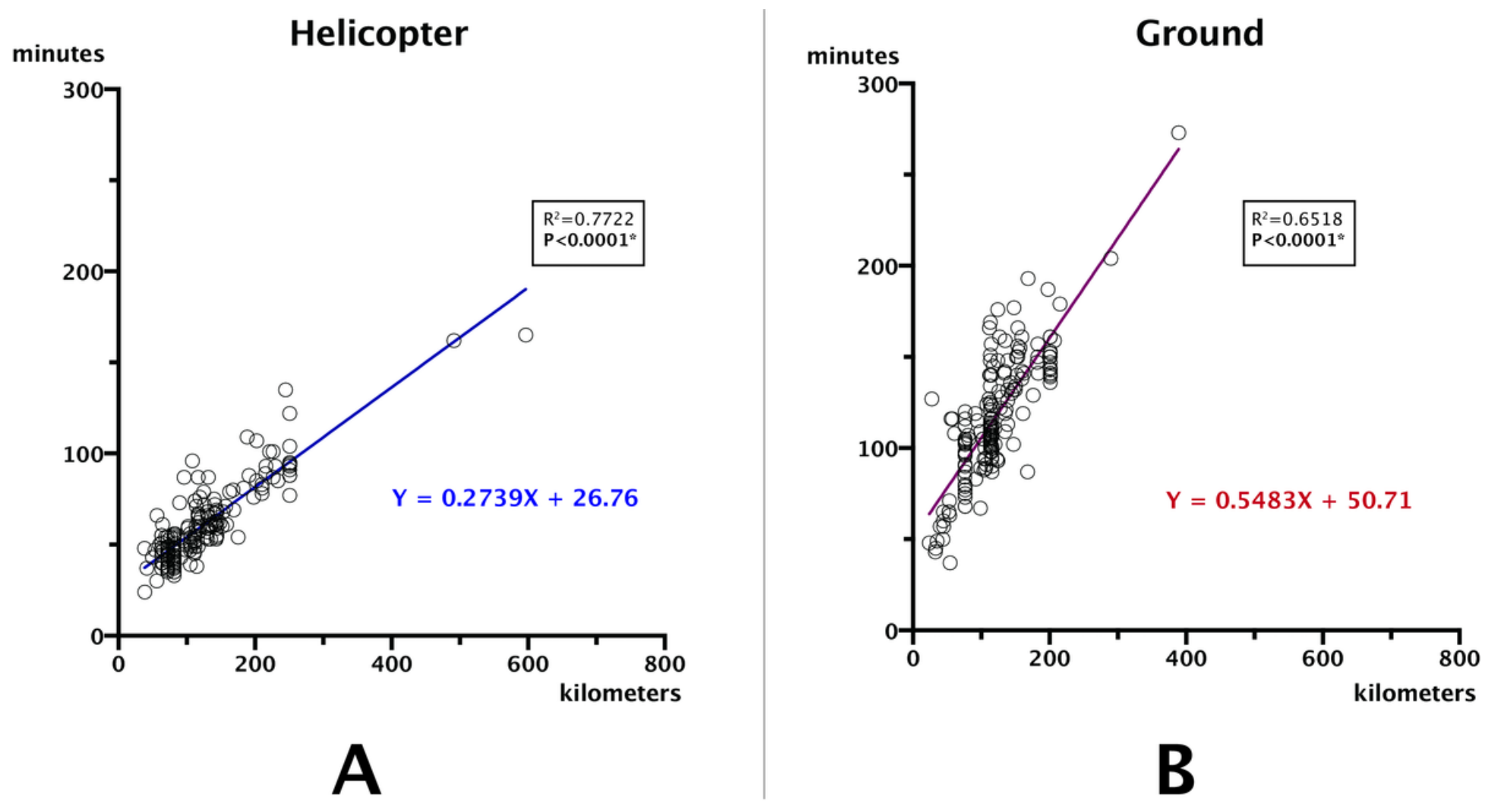

Figure 5

The graphical plots of the distance and time in HEMS (A) and GEMS (B).
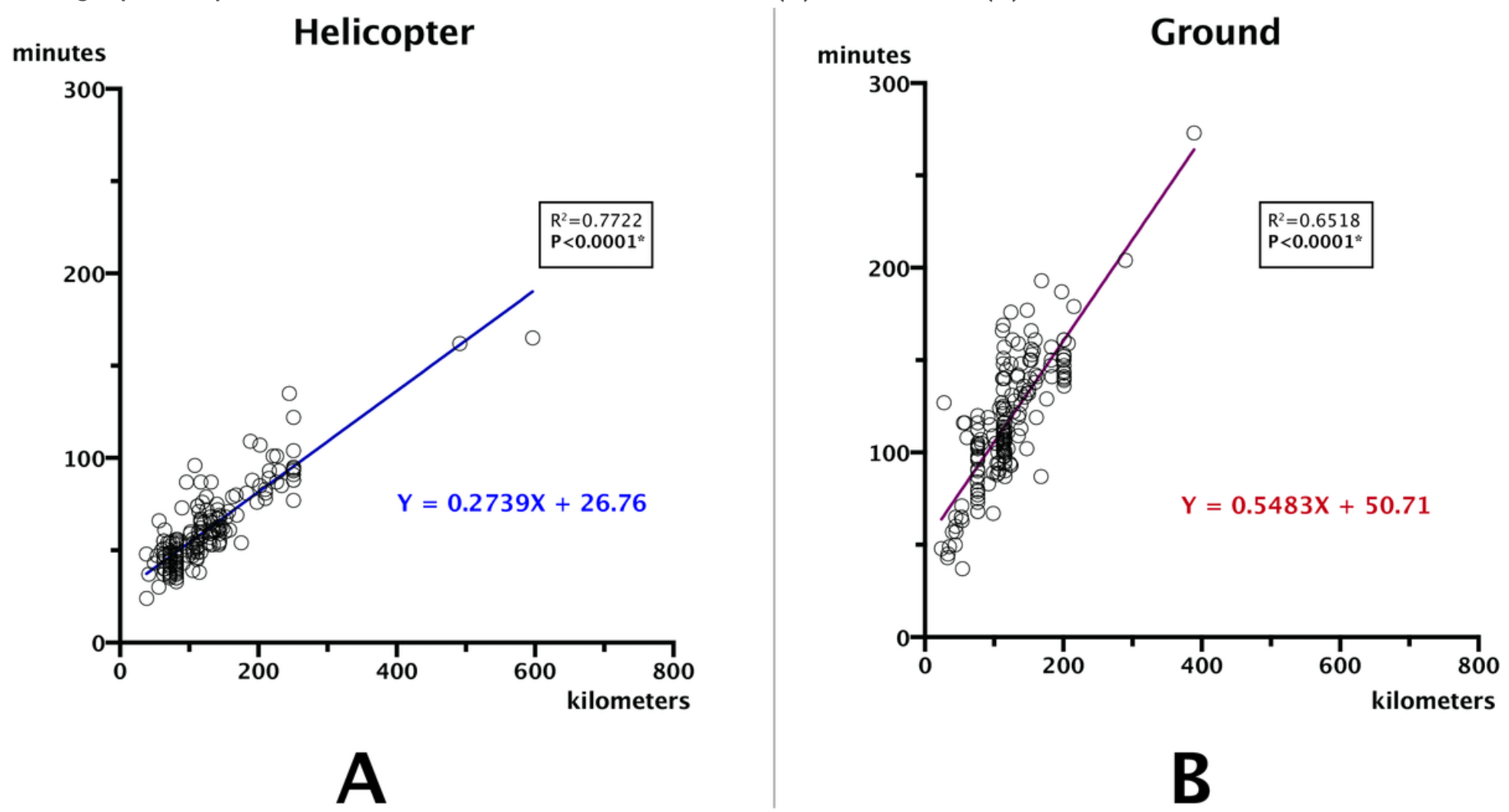
Figure 5

The graphical plots of the distance and time in HEMS (A) and GEMS (B).

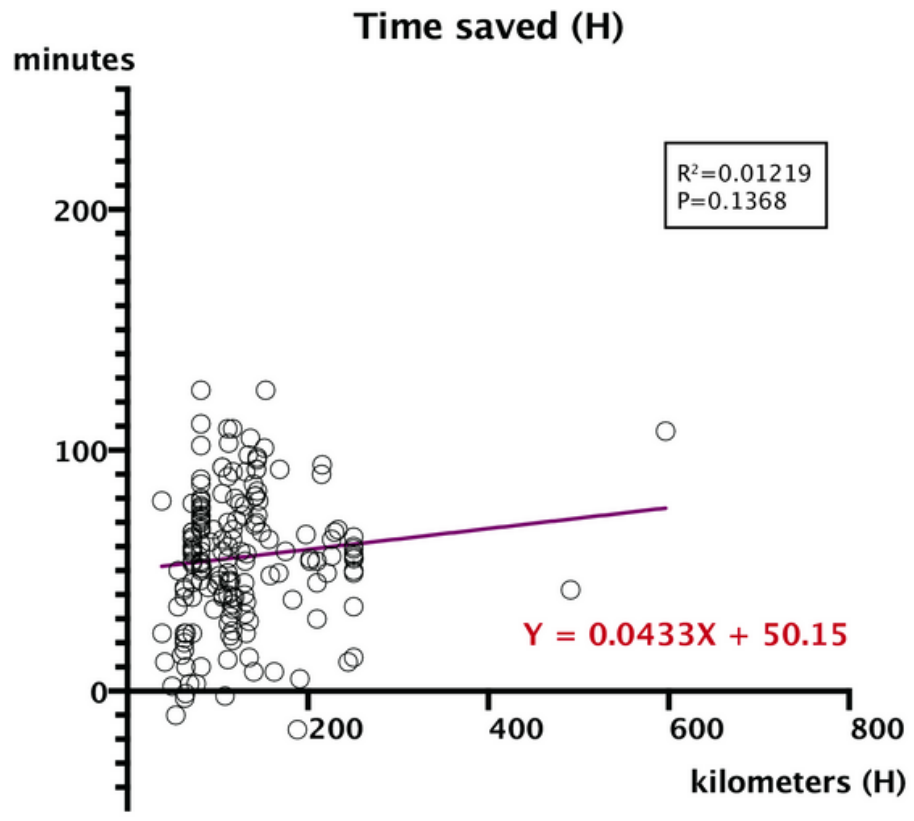

minutes

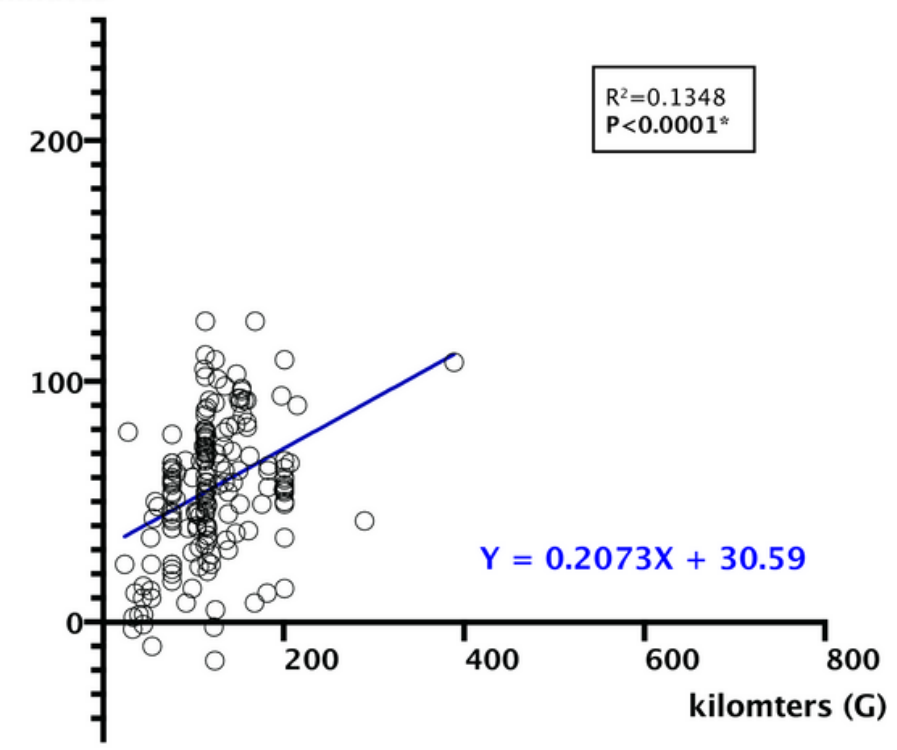

B

Figure 6

The graphical plots of the time saved based on the distance of HEMS (A) and GEMS (B).

\section{minutes}

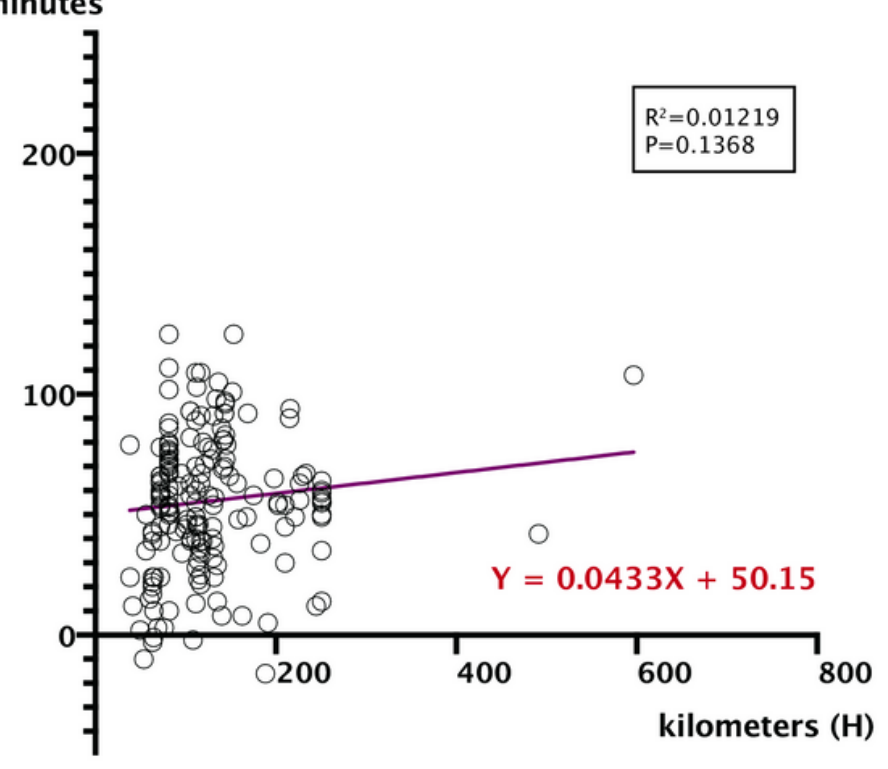

Time saved $(\mathrm{H})$

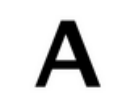

Time saved (G)

minutes

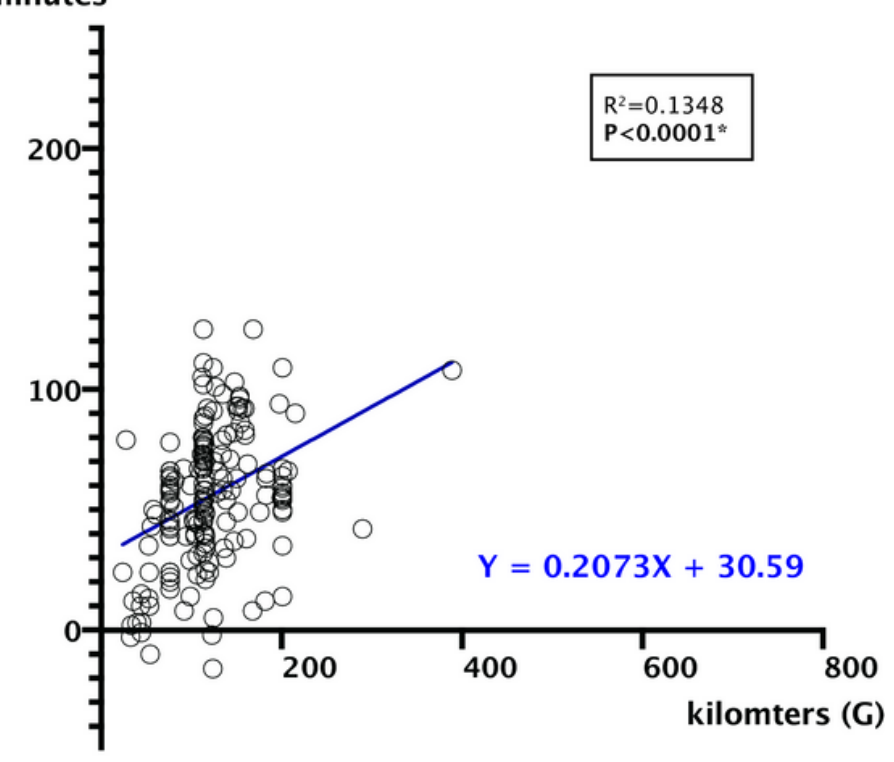

B

Figure 6 
The graphical plots of the time saved based on the distance of HEMS (A) and GEMS (B). 